\title{
Toxicity and anthelmintic efficacy of chitosan encapsulated bromelain against gastrointestinal strongyles in Small East African goats in Kenya
}

\author{
Shukuru Wasso ${ }^{1}$, Naomi Maina ${ }^{1,2}$ and John Kagira ${ }^{3}$
}

1. Department of Molecular Biology and Biotechnology, Pan African University, Institute of Basic Sciences, Technology and Innovation, P.O. Box 62000-00200, Nairobi, Kenya; 2. Department of Biochemistry, Jomo Kenyatta University of Agriculture and Technology, P.O. Box 62000-00200, Nairobi, Kenya; 3. Department of Animal Sciences, Jomo Kenyatta University of Agriculture and Technology, P.O. Box 62000-00200, Nairobi, Kenya.

Corresponding author: John Kagira, e-mail: jkagira@gmail.com

Co-authors: SW: wasso.dieudo@gmail.com, NM: nmaina@jkuat.ac.ke

Received: 05-09-2019, Accepted: 04-12-2019, Published online: 25-01-2020

doi: www.doi.org/10.14202/vetworld.2020.177-183 How to cite this article: Wasso S, Maina N, Kagira J (2020) Toxicity and anthelmintic efficacy of chitosan encapsulated bromelain against gastrointestinal strongyles in Small East African goats in Kenya, Veterinary World, 13(1): 177-183.

\begin{abstract}
Background and Aim: The development of resistance to anthelmintic drugs has prompted research into alternative methods of controlling intestinal nematodes in ruminants. This study aimed at evaluating the in vitro and in vivo anthelmintic efficacy and toxicity of chitosan encapsulated bromelain in Small East African goats in Kenya.
\end{abstract}

Materials and Methods: Adult mortality assay was performed using live Haemonchus contortus worms treated with encapsulated bromelain solution ranging from $0.125 \mathrm{mg} / \mathrm{ml}$ to $2 \mathrm{mg} / \mathrm{ml}$. Percentage mortality of worms was calculated after $24 \mathrm{~h}$ and the lethal concentration $50 \%\left(\mathrm{LC}_{50}\right)$ determined. For the in vivo study, 18 healthy male indigenous goats were divided into six groups of three goats each. The encapsulated bromelain was orally administered in increasing dosages $(3-30 \mathrm{mg} \mathrm{kg})$ once daily, for 14 days. The packed cell volume (PCV), aspartate aminotransferase (AST), alanine aminotransferase (ALT), urea, creatinine, and fecal egg count (FEC) were determined on a weekly basis. At the end of the study, the goats were sacrificed and gross pathology and histopathology of main organs assessed.

Results: Albendazole had the highest $(\mathrm{p}<0.05)$ anthelmintic effect on the worms. $\mathrm{An} \mathrm{LC}_{50}$ of $0.05 \mathrm{mg} / \mathrm{ml}, 0.445 \mathrm{mg} / \mathrm{ml}$, and $0.155 \mathrm{mg} / \mathrm{ml}$ was observed for albendazole, plain bromelain, and encapsulated bromelain, respectively. The PCV of treated and untreated goats did not show any significant difference $(\mathrm{p}>0.05)$, varied from $29.3 \%$ to $35.1 \%$, and was within the normal range of the animal. Likewise, no significant differences $(\mathrm{p}>0.05)$ were observed between the AST, ALT, urea, and creatinine levels of treated and the control (non-treated) goats. No adverse clinical symptoms, toxicity of the main organs, and mortality in goats were associated with the chitosan encapsulated bromelain after administration of dose up to $30 \mathrm{mg} / \mathrm{kg}$ for 14 days. Therefore, the lethal dose 50 of encapsulated bromelain may be considered to be $>30 \mathrm{mg} / \mathrm{kg}$. On day 28 posttreatment, the encapsulated bromelain showed a higher in vivo FEC reduction (68.8\%) as compared to the plain bromelain $(32.4 \%)$

Conclusion: Our results show that bromelain encapsulated in chitosan may be safe and effective in reducing the burden of gastrointestinal tract strongyle nematodes in goats. However, there is a need for further studies to establish the dosage of the encapsulated bromelain to be administered in a single dose for the treatment of goats against gastrointestinal strongyles. In addition, species-specific studies on the efficacy of encapsulated bromelain on strongyles are necessary to evaluate its effectiveness against the entire Strongyloididae family.

Keywords: anthelmintic efficacy, bromelain, chitosan, goats, nanoencapsulation, toxicity.

\section{Introduction}

Helminthosis is an important disease associated with the infection of helminths in the gastrointestinal tract of ruminants [1]. Currently, it is one of the most economically important diseases of livestock in tropics and has a significant economic impact on the well-being of farmers in developing countries [2]. The disease causes the suppression of weight gain, reduction of reproductive performances and leads to high

Copyright: Wasso, et al. Open Access. This article is distributed under the terms of the Creative Commons Attribution 4.0 International License (http://creativecommons.org/licenses/by/4.0/), which permits unrestricted use, distribution, and reproduction in any medium, provided you give appropriate credit to the original author(s) and the source, provide a link to the Creative Commons license, and indicate if changes were made. The Creative Commons Public Domain Dedication waiver (http://creativecommons.org/ publicdomain/zero/1.0/) applies to the data made available in this article, unless otherwise stated. mortality in extreme cases $[3,4]$. Farmers rely on the aggressive use of anthelmintics to treat and control helminthosis. While commercial anthelmintic usage has shown beneficial effects on animal health, it is also associated with problems, including consumer concern over potential synthetic drug residues in animal products $[5,6]$, and loss of efficacy as a result of the emergence of resistance [7,8]. Given the widespread occurrence of resistance, there is a need for new alternatives involving the development of new drugs with different modes of action, with a specific focus on products arising from plants [9].

Pineapple fruits, stem, and peels are good sources of bromelain which have been proven to have anthelmintic activities [10]. The use of bromelain as anthelmintics has faced some constraints including administration challenges [11]. Studies have shown 
that after administration, bromelain anthelmintic activity is lowered by the low $\mathrm{pH}$ found in the abomasum of ruminants. Moreover, the rumen microbiota can cause deterioration of the drug efficacy, resulting in an ineffective contact between worms and drugs [11]. The study by Hunduza [12] showed that the encapsulation of bromelain with chitosan enhanced it's in vitro activity against all the stages of Haemonchus contortus isolated from goats. It revealed that encapsulated bromelain had a higher $(p>0.05)$ egg hatch inhibition activity (half maximal inhibitory concentration $\left.\left[\mathrm{IC}_{50}=0.249\right]\right)$ than extracted $\left(\mathrm{IC}_{50}=0.325\right)$ and pure bromelain $\left(\mathrm{IC}_{50}=0.327\right)$. The study also indicated that encapsulated bromelain had significantly higher $(\mathrm{p}<0.05)$ absorbance than that of plain bromelain at low $\mathrm{pH}$ (2.0 and 3.0) showing that chitosan nanocarriers stabilize and maintain the activity of bromelain. This implies that bromelain encapsulated in chitosan can be used to target and affect parasites found in the abomasum of ruminants which has a low $\mathrm{pH}$. However, there is a need to further conduct research on the drug by evaluating its toxicity and efficacy against helminthosis in vivo in goats.

Therefore, this study aimed at evaluating the in vitro and in vivo efficacy and toxicity of a bromelain chitosan formulation in Small East African goats in Kenya.

\section{Materials and Methods \\ Ethical approval}

Approval for animal experiments was obtained from the Jomo Kenyatta University of Agriculture and Technology (JKUAT) Animal Ethics Committee (REF: JKU/2/4/896B). The protocols were approved by the Institutional Animal Care and Use Committee at JKUAT and conducted in compliance with Kenya's National ethical standards to minimize animal suffering.

\section{Study site}

The study was carried out at JKUAT, Kiambu County, Kenya. The university is located at latitude $1^{\circ} 05 \mathrm{~S}$ and longitude $37^{\circ} 00 \mathrm{E}$. It lies at an altitude of $1525 \mathrm{~m}$ above sea level and receives an annual rainfall of $850 \mathrm{~mm}$ with temperatures ranging from $13^{\circ} \mathrm{C}$ to $26^{\circ} \mathrm{C}[13]$.

\section{Study animals}

Eighteen Small East African healthy male indigenous goats, aged between 8 and 30 months old and weighing between 13 and $21 \mathrm{~kg}$, were purchased from local farmers. They were ear-tagged and kept in a goat house where they were acclimatized to the diet over the course of 14 days before commencing the study. Animals were group-housed in pens of size $2 \mathrm{~m} \times 2 \mathrm{~m}$ (three goats in each) inside the main goat house which was located within the JKUAT. Each animal was screened for the presence of strongyle eggs by fecal egg count (FEC) examination before the start of the experiment. Goats were fed on $1.5 \mathrm{~kg}$ of concentrate feed and $1 \mathrm{~kg}$ of wheat hay twice each day (at 9 a.m. and 3 p.m.). The concentrate feed comprised beet liquid molasses, maize germ, and soybean meal (Aroma Feed Suppliers, Kenya). Supplementation of essential minerals was done using feed blocks (Aroma Feed Suppliers, Kenya). Along with the experiment, albendazole (Sigma-Aldrich, USA) was administered to goats as a positive control. Commercial bromelain (SigmaAldrich, USA) was used as a parallel control test.

\section{Extraction of bromelain and encapsulation in chitosan nanoparticles}

Bromelain extraction was performed as described by Kahiro et al. [14]. The extracted bromelain was purified using a $10 \mathrm{kDa}$ dialysis membrane. The ionic gelation method was used to encapsulate bromelain into chitosan [12] where equal volume $(30 \mathrm{ml})$ of extracted bromelain $(4 \mathrm{mg} / \mathrm{ml})$ was mixed with $1 \%$ sodium tripolyphosphate (STPP) and rotary mixed for $1 \mathrm{~min}$. Using a syringe, $12 \mathrm{ml}$ of the bromelain-STPP mixture was added to $20 \mathrm{ml}$ of $1 \%$ chitosan under vigorous and continuous stirring. The resultant suspension was centrifuged at $15,000 \mathrm{rpm}$ for $45 \mathrm{~min}$ and the obtained pellet washed with distilled water before freeze-drying. The aliquots of bromelain loaded chitosan nanocarrier pellet were frozen at $-60^{\circ} \mathrm{C}$ and placed in the freeze-dryer (MRC equipment manufacturer, Israel). The freeze-drying was allowed to run until all the samples were completely dried. Successful conjugation of bromelain to the chitosan nanoparticles was confirmed by Fourier transform infrared spectrophotometer analysis.

\section{In vitro adult worm mortality assay}

Adult mortality assay was conducted according to the procedure by Eguale et al. [15] and Hunduza [12]. Briefly, ten actively moving worms were placed in Petri dishes and exposed to encapsulated bromelain solution ranging from $0.125 \mathrm{mg} / \mathrm{ml}$ to $2 \mathrm{mg} / \mathrm{ml}$. Albendazole prepared in concentrations ranging from $0.125 \mathrm{mg} / \mathrm{ml}$ to $2 \mathrm{mg} / \mathrm{ml}$ was used as the positive control while phosphate-buffered saline was used as the negative control. Commercial bromelain was also prepared in concentrations ranging from $0.125 \mathrm{mg} / \mathrm{ml}$ to $2 \mathrm{mg} / \mathrm{ml}$ and was used as a parallel control test. Each test was done in triplicate. After $24 \mathrm{~h}$, the number of live and dead worms was counted and the percentage mortality calculated using the formula:

$$
\% \text { Mortality } \equiv \frac{\text { Number of dead worms }}{\text { Total number of worms }} \times 100
$$

\section{Animal treatments}

Treatment groups were formed after randomization based on the number of eggs per gram (EPG) of feces (EPG values), such that the mean EPG of the animals in each group was more than 500 [16]. Each group had three animals. The treatment was done orally every morning ( 9 a.m.) for 14 days. Groups 1, 2, and 3 received $30 \mathrm{mg} / \mathrm{kg}, 10 \mathrm{mg} / \mathrm{kg}$, and $3 \mathrm{mg} / \mathrm{kg}$ of encapsulated bromelain, respectively. Group 4 received 
$30 \mathrm{mg} / \mathrm{kg}$ of plain bromelain. Group 5 was the positive control (Albendazole, $7.5 \mathrm{mg} / \mathrm{kg}$ body weight) and Group 6 was the negative infected non-treated control. The above dosages were chosen following the World Association for the Advancement of Veterinary Parasitology guidelines for dose determination [17] and the results of the bromelain toxicity tests obtained in the previous studies [18-20].

\section{In vivo toxicity assessment}

Clinical observations

Goats were fasted overnight before dosing. Following the period of fasting, the animals were weighed and then the test substance was administered orally using drenching guns. Observations were made and recorded systematically and continuously as per the guidelines [21]. Animals were observed individually during the entire study period. Special attention was given during the first $4 \mathrm{~h}$ and daily thereafter, for a total of 14 days to observe any death or changes in general behavior and other physiological activities. Observations included changes in skin and fur, eyes and mucous membranes, respiratory system, and behavior pattern. Attention was also directed to observations of salivation, diarrhea, lethargy, and sleep in the animals [21].

Temperature and bodyweight of goats were measured at 09:00 am using a digital thermometer (Kruuse Digital Thermometer; Jørgen Kruuse) and a $100 \mathrm{~kg}$ spring balance scale (Salter Model, Capital Scales Pretoria, South Africa), respectively. This was done before treatment and once a week during the experiment period. Changes in the weight of individual goats were calculated and compared with that of the control animals. Changes were considered as a result of the adverse effects of drugs if the body weight loss observed was more than $10 \%$ of the initial recorded body weight [22]

\section{Sample collection}

Blood samples $(3 \mathrm{ml})$ from each goat were drawn from the jugular vein in ethylenediaminetetraacetic acid test tubes using $3 \mathrm{ml}$ syringes with 3/4-inch, 20-gauge needles. This was done at 09:00 am weekly.

\section{Packed cell volume (PCV)}

The PCV was determined using the microhematocrit method $[23,24]$. Briefly, an aliquot of blood with anticoagulant from each goat was put in micro-capillary tubes and then centrifuged at $14,000 \mathrm{rpm}$ for $10 \mathrm{~min}$. After centrifugation, samples were analyzed for PCV using a micro-capillary reader (Hawksley, England).

\section{Determination of serum biochemical parameters}

Aspartate aminotransferases (AST), alanine aminotransferases (ALT), urea, and creatinine were analyzed using standard diagnostic test kits on automated clinical biochemistry analyzer (Reflotron Plus System ${ }^{\circledR}$, model: Cobas 4800 Detection Analyzer; Mumbai, India).

\section{Gross pathology and histopathology}

At the end of the experimental period, the goats were sacrificed and examined for gross pathology. Parts of the following organs were preserved in $10 \%$ buffered formalin: Liver, kidney, spleen, and heart. Thereafter, the organs were processed for histopathology and the prepared slides examined under the microscope using the procedure as described by Slaoui and Fiette [25].

\section{Assessment of the in vivo anthelmintic efficacy}

Fecal samples were collected once a week, for 4 weeks, from the rectum of the goats using fresh gloves. Aliquots of $2 \mathrm{~g}$ of the fecal sample from each goat were placed in a plastic bottle (Indosurgicals Pvt. Ltd., New Delhi, India) for analysis.

The fecal samples were analyzed using a modified McMaster technique [26] with a precision of 100 EPG of feces using an Olympus B 201 microscope (Optical Element Corporation, Melville, USA) at 10×. FEC reduction (FECR) percentage was calculated using the formula:

$$
\% \text { FECR }=100 \times\left[1-\left(\mathrm{T}_{2} / \mathrm{T}_{1}\right)\right]
$$

$\mathrm{T}_{1}=$ Mean pre-treatment FEC in treatment group $\mathrm{T}_{2}=$ Mean post-treatment $\mathrm{FEC}$ in treatment group [27].

\section{Statistical analysis}

All statistical analyses and graphical presentations were carried out using R (version 3.6.0) (Foundation for Statistical Computing, Vienna, Austria) and GraphPad (Version 7.02) (GraphPad Software, Inc., La Jolla, CA, USA), respectively. Tests of significance for different drug concentrations on worm mortality were conducted by analysis of variance (ANOVA) and the significance level was set at $p<0.05$. Regression analysis between the log concentrations and probit-transformed responses was used to determine the lethal concentration $50 \%\left(\mathrm{LC}_{50}\right)$. Pre- and post-treatment comparisons of FEC, PCV, weight, and temperature were done using ANOVA $(\mathrm{p}<0.05)$.

\section{Results}

\section{In vitro worm mortality assay}

At all concentrations, albendazole had the greatest effect on the worms with $1 \mathrm{mg} / \mathrm{ml}$ achieving $100 \%$ worm mortality. Encapsulated bromelain showed higher activity compared to the plain bromelain and achieved $100 \%$ worm mortality at $1 \mathrm{mg} / \mathrm{ml}$. Albendazole had significantly $(\mathrm{p}<0.05)$ higher activity than encapsulated bromelain and plain bromelain. The $\mathrm{LC}_{50}$ observed were $0.05 \mathrm{mg} / \mathrm{ml}, 0.155 \mathrm{mg} / \mathrm{ml}$, and $0.445 \mathrm{mg} / \mathrm{ml}$ for albendazole, encapsulated bromelain, and plain bromelain, respectively (Figure-1).

\section{Encapsulated bromelain toxicity assessment Clinical observations}

Administration of dose up to $30 \mathrm{mg} / \mathrm{kg}$ encapsulated bromelain did not reveal any mortality in goats 
during the entire observation period. Therefore, lethal dose $50\left(\mathrm{LD}_{50)}\right.$ of encapsulated bromelain may be considered to be $>30 \mathrm{mg} / \mathrm{kg}$. No treatment-related clinical symptoms of toxicity were observed during the experimental period at any of the three doses of encapsulated bromelain, as well as for the plain bromelain $(30 \mathrm{mg} /$ $\mathrm{kg})$ and albendazole $(7.5 \mathrm{mg} / \mathrm{kg})$ used as parallel controls. The skin, fur, mucous membrane, urination, water intake, and food intake of goats were found to be normal before and after treatment. Lethargy, diarrhea, inactivity,

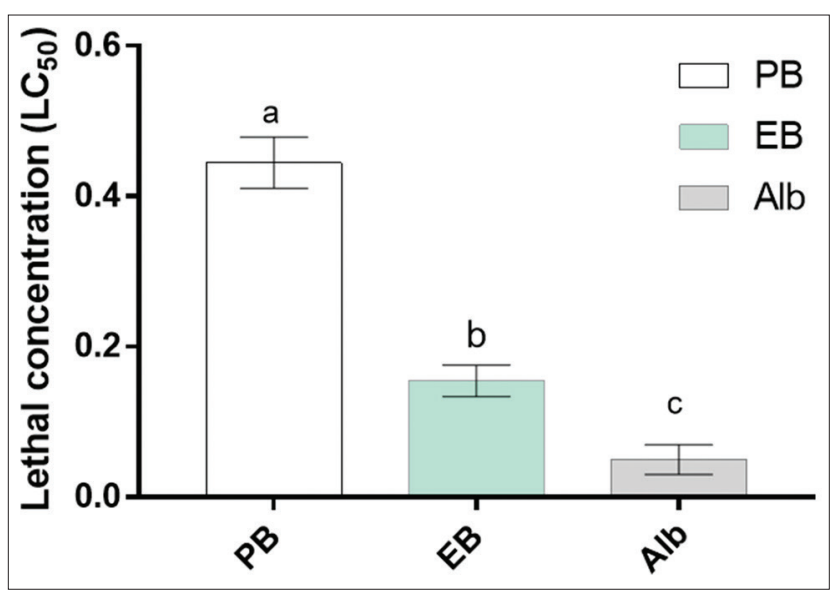

Figure-1: Mean lethal concentration $50 \%$ of bromelain, encapsulated bromelain, and albendazole. Data represent means with standard deviations of three replicates analyzed using $R$ version 3.6.0. Small letters on top of each bar compare means, according to Tukey's honestly significant difference test $(p \leq 0.05)$. Different letters indicate significantly different values. PB: Plain bromelain, EB: Encapsulated bromelain, Alb: Albendazole. rapid breathing, excessive salivation, liquid secretion from eyes, and rapid breathing were not observed. Goat body temperatures varied from $38.1^{\circ} \mathrm{C}$ to $39.2^{\circ} \mathrm{C}$, which is within the normal range of the animal [28]. No significant variation of temperature and body weight $(\mathrm{p}<0.05)$ was observed between the control non-treated goats and the encapsulated bromelain treated goats.

\section{Necropsy macroscopic observation and histological examination}

No treatment-related pathological changes of internal organs were observed in necropsy examination. Hematoxylin and eosin staining of liver showed normal hepatic architecture, hepatocytes, and hepatic sinusoids. Histological assay of the kidney from encapsulated bromelain treated groups showed normal renal architecture with a normal appearance of glomerulus and tubules. The spleen appeared normal with no histopathological alteration. Heart sections of encapsulated bromelain treated groups presented a normal myocardial architecture (Figure-2).

\section{Effect of the plant extract on the PCV and serum biochemical parameters}

The PCV of untreated goats varied between $29.3 \%$ and $35.1 \%$. The mean PCV of treated goats was similar to that of the control untreated group ( $\mathrm{p}>0.05)$. ALT and AST levels of untreated goats ranged from 14.07 to $16.17 \mathrm{U} / \mathrm{L}$ and 105.6 to $115.5 \mathrm{U} / \mathrm{L}$, respectively, which were within the normal range [29]. No significant difference $(\mathrm{p}>0.05)$ was observed between the AST and ALT levels of treated and the control
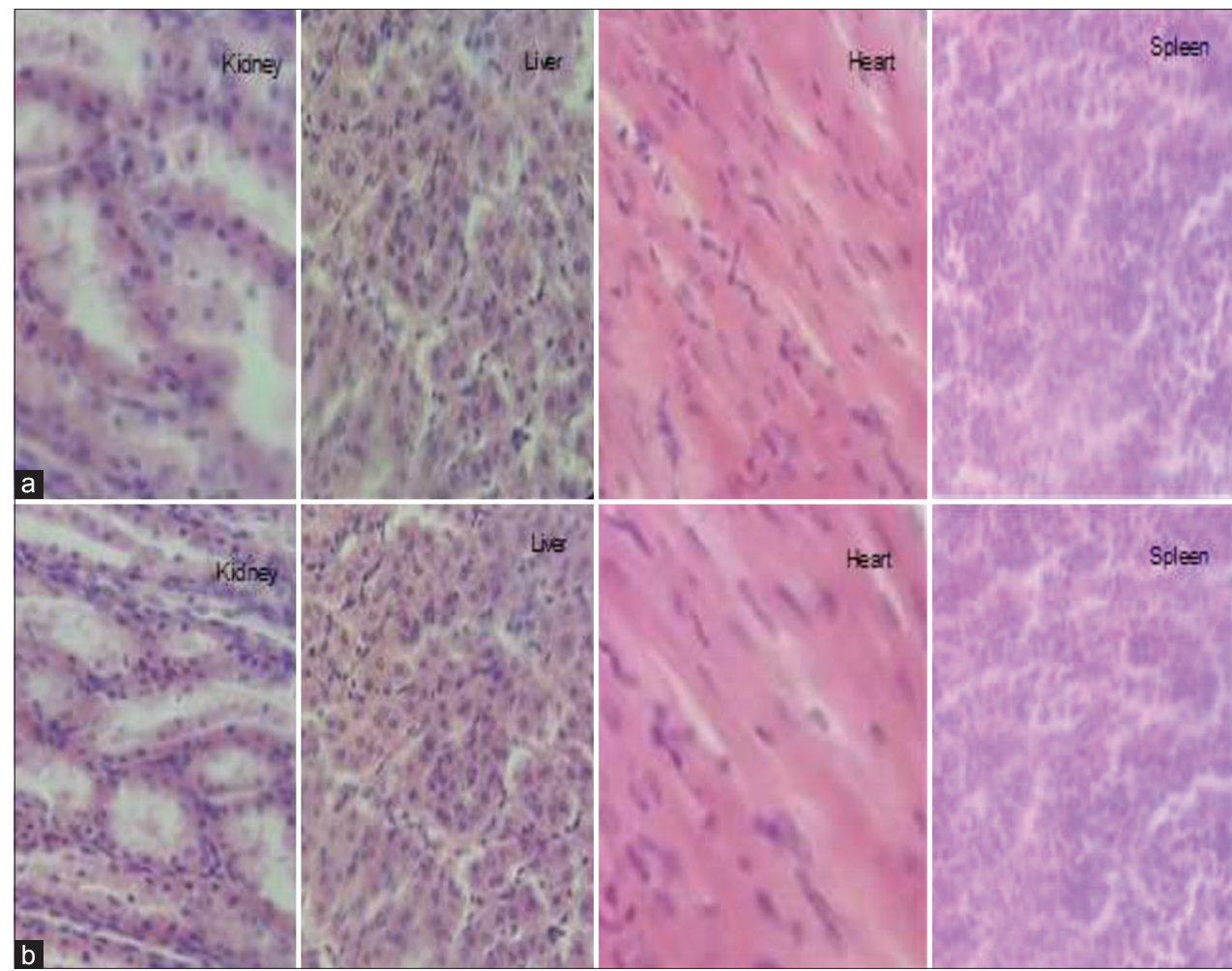

Figure-2: Histological examinations of the kidney, liver, heart, and spleen of goats after 14 days of repeated-dose toxicity study. Representative photomicrographs from kidney, liver, heart, and spleen sections stained with hematoxylin and eosin $(\mathrm{H} \& \mathrm{E})$, respective groups: (a) Control non-treated group, (b) encapsulated bromelain treated group (30 mg/kg), H\&E 400×. 
non-treated goats. Likewise, urea and creatinine levels of untreated goats varied from 5.6 to $6.3 \mathrm{mmol} / \mathrm{L}$ and 55.4 to $63.07 \mu \mathrm{mol} / \mathrm{L}$, respectively, and were within the normal range of the animal [29]. There was no significant difference between the urea and creatinine levels of treated goats and the control non-treated goats.

\section{In vivo anthelmintic efficacy assessment}

The percentage reduction in strongyle eggs was significantly higher $(\mathrm{p}<0.05)$ for the goats treated with $7.5 \mathrm{mg} / \mathrm{kg}$ of albendazole than those treated with encapsulated bromelain at any of the three tested doses $(30,10$, and $3 \mathrm{mg} / \mathrm{kg})$. Similarly, a significant $(\mathrm{p}<0.05)$ gradual increase in percentage reduction of strongyles eggs was observed over time for goats treated with the plain and encapsulated bromelain. On $28^{\text {th }}$ day post-treatment, $68.8 \%, 56.6 \%$, and $5 \%$ strongyle egg reduction were recorded for goats treated with 30, 10, and $3 \mathrm{mg} / \mathrm{kg}$ of encapsulated bromelain, respectively. In addition, $32.4 \%$ and $96.5 \%$ strongyle egg reduction was noted for goats treated with $30 \mathrm{mg} / \mathrm{kg}$ of plain bromelain and $7.5 \mathrm{mg} / \mathrm{kg}$ of albendazole, respectively. In contrast, the percentage egg count for the negative control group increased by $22 \%$ (Figure-3).

\section{Discussion}

The current study was geared toward evaluating the in vitro and in vivo efficacy and toxicity of a bromelain chitosan formulation which can extend the release of the drug. The in vitro results demonstrated that albendazole had higher anthelmintic activity than encapsulated bromelain as well as plain bromelain. This is consistent with the findings by Hunduza [12] who also evaluated the anthelmintic activity of bromelain encapsulated in chitosan nanocarriers against $H$. contortus isolated from naturally infected goat and showed that albendazole had the greatest effect on the worms followed by encapsulated bromelain and extracted bromelain.

The observed albendazole and bromelain $\mathrm{LC}_{50 \mathrm{~s}}$ are comparable to those obtained by Cheruiyot [30] and Hunduza [12]. The small difference could be related to varying quality and source of bromelain [31]. The anthelmintic mechanism of action of pineapple cysteine proteinases is well documented $[32,33]$. These enzymes attack protein targets in the cuticle leading to weakening of the cuticle, blistering and rupture, and subsequent release of internal tissues. These eventually lead to the death of the worm. This property is not limited to the enzymes from pineapple and papaya but has been reported in papain homologs from figure and lattices of other plants [32-34].

Similar to the findings of this study, Dutta and Bhattacharyya [35] did not observe any toxicity after oral administration of acute and sub-acute doses of the aqueous extract of Ananas comosus (pineapple) crown leaf to rats. According to Taussig et al. [18], bromelain has very low toxicity and its $\mathrm{LD}_{50}$ has been evaluated to be $>10 \mathrm{~g} / \mathrm{kg}$ in mice, rates, and rabbits. Pavan et al. [19] reported that daily administration of

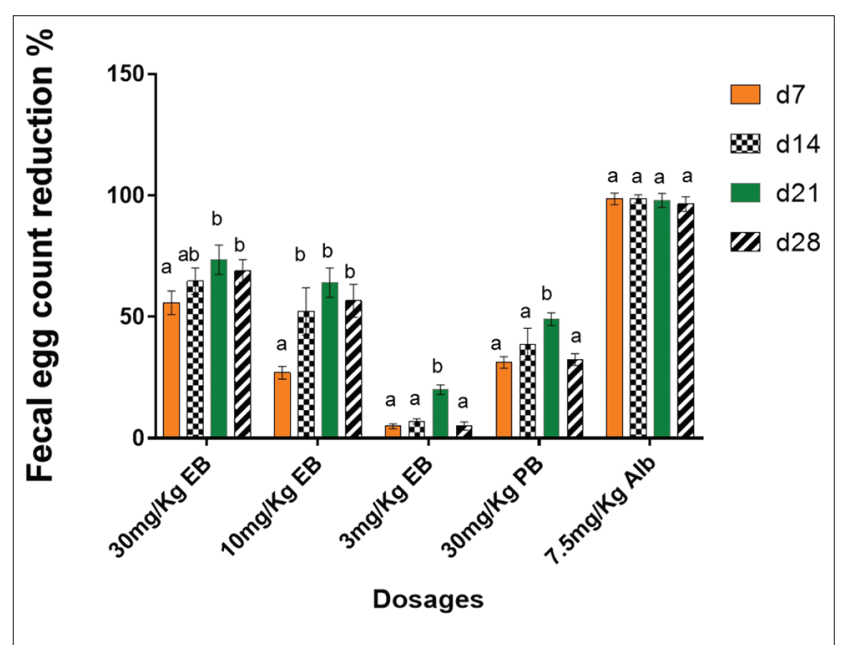

Figure-3: Fecal egg count reduction test. Positive values indicate a relative reduction of the number of EPG of feces and negative values a relative increase. Data represent means with standard deviations of three replicates analyzed using $R$ version 3.6.0. Small letters on top of each bar compare means at different days post-treatment according to Turkey's honestly significant difference test $(p \leq 0.05)$. Different letters indicate significantly different values. FECR: Fecal egg count reduction, PB: Plain bromelain, EB: Encapsulated bromelain, Alb: Albendazole, EPG: Number of eggs per gram of feces, d7: Day 7 posttreatment, d14: Day 14 post-treatment, d21: Day 21 posttreatment, d28: Day 28 post-treatment.

bromelain to dogs in an increasing level up to $750 \mathrm{mg} / \mathrm{kg}$ showed no toxic effects after 6 months. Corroborating our results, Moss et al. [20] did not find any alteration in the histology of heart, kidney, or hematological parameters after administration of $1500 \mathrm{mg} / \mathrm{kg}$ bromelain per day to rats. The PCV observed in this study was lower compared to the values (32.5-43.7\%) reported by Al-Bulushi et al. [36] for Sahrawi goats. Earlier reports for Jabali goats showed PCV values ranging from $37.4 \%$ to $43.7 \%$ [36]. Despite the small difference observed, the obtained PCV values were within the normal range of the animal [37]. The observation that there were no significant differences between the PCV of treated and control non-treated goats indicates that the administration of encapsulated bromelain does not affect erythrocyte production and physiology. The serum creatinine, urea, ALT, and AST levels were within the normal range of the animal and did not show any significant difference between the treated and the negative control non-treated goats indicating normal functioning kidneys and liver. The range of goat ALT level observed in this study is comparable with the finding by Tibbo et al. [38] who indicated that the ALT level of indigenous Arsi-Bale, Central Highland and Long-eared Somali goat breeds ranged from 14.0 to $20.2 \mathrm{U} / \mathrm{L}$. The obtained values for urea were in agreement with the report of Chikwanda and Muchenje [39] and also Kaneko et al. [40] who reported urea level ranging from 3.57 to $7.14 \mathrm{mmol} / \mathrm{L}$, which was in the normal range of the animal.

As compared to the findings of this study, Domingues et al. [41] reported a lower efficacy for 
bromelain in sheep infected with $H$. contortus. The disparity between the anthelmintic efficacy reported by Domingues et al. [41] and the findings of this study can be attributed to the differences in the administered dosages and to the fact that they used $H$. contortus infected sheep while the present study dealt with goats. In addition, in this study, the drug was administered for 14 days in contrast to Domingues et al. [41] single dose. In the present study, encapsulated bromelain had higher activity than plain bromelain, thus, it is clear that the encapsulation process increased the efficacy of bromelain. A similar result was reported by Hunduza [12]. Ribeiro et al. [42] further demonstrated that the encapsulation of extracted plant oils in chitosan nanoparticles leads to an increase in their efficacy against $H$. contortus. The observed increased activity of encapsulated bromelain as compared to plain bromelain can be attributed to the fact that encapsulation of enzymatic drugs stabilizes the protein structure, promotes an active-controlled release and stabilizes the activity presenting greater efficacy [43].

\section{Conclusion and Recommendations}

The current study demonstrates that oral administration of chitosan encapsulated bromelain up to a dosage of $30 \mathrm{mg} / \mathrm{kg}$ is not associated with any adverse clinical symptoms, toxicity of the main organs, and mortality in goats. The encapsulation of bromelain in chitosan enhances its anthelmintic properties in vitro and in vivo, and thus encapsulated bromelain can act as an important substitute to synthetic anthelmintic drugs where anthelmintic resistance has developed. However, further experiments with infected animals are essential to establish the dosage of the encapsulated bromelain to be administered in a single dose for the treatment of goats against gastrointestinal strongyles. In addition, species-specific studies on the efficacy of encapsulated bromelain on strongyles are necessary to evaluate its effectiveness against the entire Strongyloididae family.

\section{Author's Contributions}

All authors conceived and designed the experiment. SW and JK performed the experiment. NM performed the biochemical assays. SW and JK analyzed and wrote the manuscript. All authors read and approved this manuscript.

\section{Acknowledgments}

This work was done through financial support by the Pan African University (MB 300-0002/18), Jomo Kenyatta University of Agriculture and Technology (JKUAT) and the Africa-ai-Japan Project. The authors are grateful to Matuu and Kiserian farmers for provision of goats and acknowledge the technical assistance provided by JKUAT staff, including Dr. Lewis Macharia, Grace Kimani, Perminus Kimathi, and Michael Oduor. All authors read and approved the final draft of the article.

\section{Competing Interests}

The authors declare that they have no competing interests.

\section{Publisher's Note}

Veterinary World remains neutral with regard to jurisdictional claims in published institutional affiliation.

\section{References}

1. Bamaiyi, P. (2011) Factors militating against the control of helminthosis in livestock in developing countries. Vet. World, 5(1): 42-47.

2. Chavan, P.B., Khan, L.A., Raut, P.A., Maske, D.K., Rahman, S. and Podchalwar, K.S. (2008) Prevalence of nematode parasites of ruminants at Nagpur. Vet. World, 1(5): 140.

3. Waller, P. (2006) From discovery to development: Current industry perspectives for the development of novel methods of helminth control in livestock. Vet. Parasitol., 139(1-3): 1-14.

4. Lashari, M. and Tasawar, Z. (2011) Prevalence of gastrointestinal parasites in sheep, Southern Punjab, Pakistan. Pak. Vet. J., 31(4): 295-298.

5. Knox, D.P. (2000) Development of vaccines against gastrointestinal nematodes. Parasitology, 120(7): S43-S61.

6. Dalton, J.P. and Mulcahy, G. (2001) Parasite vaccines a reality? Vet. Parasitol., 98(1-3): 149-167.

7. Wanyangu, S.W., Bain, R.K., Rugutt, MK., Nginyi, J.M. and Mugambi, J.M. (1996) Anthelmintic resistance amongst sheep and goats in Kenya. Prev. Vet. Med., 25(3-4): 285-290.

8. Waruiru, R.M., Kogi, J.K., Weda, E.H. and Ngotho, J.W. (1998) Multiple anthelmintic resistance on a goat farm in Kenya. Vet. Parasitol., 175(2-3): 19.

9. Newman, D.J., Cragg, G.M. (2012) Natural products as sources of new drugs over the 30 years from 1981 to 2010. J. Nat. Prod., 75(3): 311-335.

10. Maurer, H.R. (2001) Bromelain: Biochemistry, pharmacology and medical use. Cell. Mol. Life Sci., 58(9): 1234-1245.

11. Buttle, D., Behnke, J., Bartley, Y., Elsheikha, H., Bartley, D., Garnett, M. and Duce, I. (2011) Oral dosing with papaya latex is an effective anthelmintic treatment for sheep infected with Haemonchus contortus. Parasit. Vectors, 4(1): 36.

12. Hunduza, A. (2018) Anthelmintic Efficacy of Bromelain Encapsulated Chitosan Nanocarrires against Haemonchus contortus, Pan African University Thesis.

13. Menge, D.M.S., Makobe, M., Monda, E.O. and Okemo, P.O. (2014) Effects of crude extracts on some selected physiological parameters of French beans (Phaseolus vulgaris) infected with rust (Uromyces appendiculatus). Afr. J. Plant Sci., 8(7): 356-363.

14. Kahiro, S.K., Kagira, J.M., Maina, N., Karanja, S.M. and Njonge, F.N. (2017) Enzymatic activity of bromelain from crude extracts of crown, peels and stem of pineapples from different agro-ecological zones of Thika region, Kenya. Asian J. Biotechnol. Bioresour. Technol., 1(2): 1-6.

15. Eguale, T., Tilahun, G., Debella, A., Feleke, A. and Makonnen, E. (2007) In vitro and in vivo anthelmintic activity of crude extracts of Coriandrum sativum against Haemonchus contortus. J. Ethnopharmacol., 110(3): 428-433.

16. Coles, G.C., Jackson, F., Pomroy, W.E., Prichard, R.K., Son-Himmelstjerna, G.V. and Silvestre, A. (2006) The detection of anthelmintic resistance in nematodes of veterinary importance. Vet. Parasitol., 136(3-4): 167-185.

17. Wood, I.B., Amaral, N.K., Bairden, K., Duncan, J.L., Kassai, T., Malone J.B Jr., Pankavich, J.A., Reinecke, R.K., Slocombe, O., Taylor, S.M. and Vercruysse, J. (1995) World 
association for the advancement of veterinary parasitology (W.A.A.V.P.): Second edition of guidelines for evaluating the efficacy of anthelmintics in ruminants (bovine, ovine, caprine). Vet. Parasitol., 58(3): 181-213.

18. Taussig, S.J., Yokoyama, M.M. and Chinen, A. (1975) Bromelain: A proteolytic enzyme and its clinical application: A review. Hiroshima J. Med. Sci., 24(2-3): 185-193.

19. Pavan, R., Jain, S., Shraddha, P., and Kumar, A. (2012) Properties and therapeutic application of bromelain: A review. Biotechnol. Res. Int., 2012(1): 1-6.

20. Moss, I.N., Frazier, C.V. and Martin, G.J. (1963) Bromelain the pharmacology of the enzyme. Arch. Int. Pharmacodyn. Ther., 145(3): 166-189.

21. OECD. (2001) Guideline for Testing of Chemicals Acute Oral Toxicity Acute Toxic Class Method. OECD, France. p14.

22. Raza, M., Al-Shabanah, O.A., El-Hadiyah, T.M. and Al-Majed, A.A. (2002) Effect of prolonged vigabatrin treatment on hematological and biochemical parameters in plasma, liver and kidney of Swiss albino mice. Sci. Pharm., 70(2): 135-145.

23. Githiori, J.B., Hogland, J., Waller, P.J. and Baker, R.L. (2004) Evaluation of anthelmintic properties of some plants used as livestock dewormers against Haemonchus contortus infection in sheep. Parasitology, 129(2): 245-253.

24. Hansen, J. and Perry, B. (1994) The Epidemiology, Diagnosis and Control of Helminth Parasites of Ruminants: A Handbook. International Livestock Research Institute, Nairobi.

25. Slaoui, M. and Fiette, L. (2011) Histopathology procedures: From tissue sampling to histopathological evaluation. In: Gautier, J.C., editors. Drug Safety Evaluation. Methods in Molecular Biology (Methods and Protocols). Vol. 691. Humana Press, Switzerland.

26. Zajac, A.Z. and Conboy, G.A. (2012), Veterinary Clinical Parasitology. $8^{\text {th }}$ ed. Wiley-Blackwell, Chichester. p8-11.

27. Kochapakdee, S., Pandey, V.S., Pralomkarn, W., Choldumrongkul, S., Ngampongsai, W. and Lawpetchara, A. (1995) Anthelmintic resistance in goats in Southern Thailand. Vet. Rec., 137(5): 124-125.

28. Swenson, M.J. and Reece, W.O. (2006) Dukes Fisiologia dos Animais Domésticos. Guanabara Koogan S.A. Rio de Janeiro.

29. Jackson, P.G. and Cockcroft, P.D. (2002) Clinical Examination of Farm Animals. Wiley-Blackwell, Hoboken.

30. Cheruiyot, K. (2017) In vitro Ovicidal Activity of Encapsulated Ethanolic Extract of Prosopis juliflora Against Haemonchus contortus Eggs, Jomo Kenyatta University of Agriculture and Technology, Thesis.

31. Bresolin, I., Silveira, E., Tambourgi, E. and Mazzola, P. (2013) Isolation and purification of bromelain from waste peel of pineapple for therapeutic application. Braz. Arch. Biol. Technol., 56(6): 971-979.

32. Stepek, G., Lowe, A.E., Buttle, D.J., Duce, I.R. and Behnke, J.M. (2006) In vitro and in vivo anthelmintic efficacy of plant cysteine proteinases against the rodent gastrointestinal nematode, Trichuris muris. Parasitology, 132(5): 681-689.

33. Stepek, G., Lowe, A.E., Buttle, D.J., Duce, I.R. and Behnke, J.M. (2007a) Anthelmintic action of plant cysteine proteinases against the rodent stomach nematode, Protospirura muricola, in vitro and in vivo. Parasitology, 134(1): 103-112.

34. Stepek, G., Lowe, A.E., Buttle, D.J., Duce, I.R. and Behnke, J.M. (2007b) The anthelmintic efficacy of plant-derived cysteine proteinases against the rodent gastrointestinal nematode, Heligmosomoides polygyrus, in vivo. Parasitology, 134(10): 1409-1419.

35. Dutta, S. and Bhattacharyya, D. (2013) Enzymatic, antimicrobial and toxicity studies of the aqueous extract of Ananas comosus (pineapple) crown leaf. J. Ethnopharmacol., 150(2): 451-445.

36. Al-Bulushi, S., Shawaf, T. and Al-Hasani, A. (2017) Some hematological and biochemical parameters of different goat breeds in sultanate of Oman "A preliminary study". Vet. World, 10(4): 461-466.

37. Radostitis, C.C., Gray, D.C. and Hinchcliff, K.K. (2000) Blood and diseases caused by trypanosomes. In: Otto, M., Clive, C., Douglas, C., Kenneth, W., Gay, C., Hinchcliff, K. and Russel, D., editors. A Textbook: Of the Diseases of Cattle, Sheep, Pigs, Goats and Horse. $9^{\text {th }}$ ed. WB Saunders Company Ltd., New York. p1877.

38. Tibbo, M., Jibril, Y., Woldemeskel, M., Dawo, F., Aragaw, K. and Rege, J.E. (2008) Serum enzymes levels and influencing factors in three indigenous Ethiopian goat breeds. Trop. Anim. Health Prod., 40(8): 657-666.

39. Chikwanda, A.T. and Muchenje, V. (2017) Grazing system and floor type effects on blood biochemistry, growth and carcass characteristics of Nguni goats. Asian-Australas $J$. Anim. Sci., 30(9): 1253-1260.

40. Kaneko, J.J., Harvey, J.W.M. and Bruss, L. (2008) Clinical Biochemistry of Domestic Animals. $6^{\text {th }}$ ed. Academic Press, Burlington, MA.

41. Domingues, L.F., Giglioti, R., Feitosa, K.A., Fantatto, R.R., Rabelo, M.D., de Sena Oliveira, M.C., Bechara, G.H., de Oliveira, G.P., Barioni Junior, W. and de Souza Chagas, A.C. (2013) In vitro and in vivo evaluation of the activity of pineapple (Ananas comosus) on Haemonchus contortus in Santa Inês sheep. Vet. Parasitol., 197(1-2): 263-270.

42. Ribeiro, J.C., Ribeiro, W.L.C., Camura-Vasconcelos, A.L.F., Macedo, I.T.F., Santos, J.M.L., Paula, H.C.B. and Bevilaqua, C.M.L. (2014) Efficacy of free and nanoencapsulated Eucalyptus citriodora essential oils on sheep gastrointestinal nematodes and toxicity for mice. Vet. Parasitol., 204(2014): 243-248.

43. Bhatnagar, P., Patnaik, S., Srivastava, A.K., Mudiam, M.K.R., Shukla, Y., Panda, A.K. and Gupta, K.C. (2014) Anti-cancer activity of bromelain nanoparticles by oral administration. J. Biomed. Nanotechnol., 10(12): 3558-3575. 